\title{
Sustained Liver Glucose Release in Response to Adrenaline Can Improve Hypoglycaemic Episodes in Rats under Food Restriction Subjected to Acute Exercise
}

\author{
Lucas K. R. Babata, ${ }_{1}^{1}$ Maria M. D. Pedrosa, ${ }^{1,2}$ Rosângela F. Garcia, ${ }^{1}$ \\ Márcia V. Peicher, ${ }^{1}$ and Vilma Aparecida Ferreira de Godoi ${ }^{1}$ \\ ${ }^{1}$ State University of Maringá, 87020900 Maringá, PR, Brazil \\ ${ }^{2}$ Department of Physiological Sciences (DFS), State University of Maringá (UEM), Avenida Colombo 5790, \\ 87020900 Maringá, PR, Brazil \\ Correspondence should be addressed to Maria M. D. Pedrosa; montserratfurlan@gmail.com
}

Received 24 July 2013; Revised 8 January 2014; Accepted 21 January 2014; Published 27 February 2014

Academic Editor: Oreste Gualillo

Copyright @ 2014 Lucas K. R. Babata et al. This is an open access article distributed under the Creative Commons Attribution License, which permits unrestricted use, distribution, and reproduction in any medium, provided the original work is properly cited.

Background. As the liver is important for blood glucose regulation, this study aimed at relating liver glucose release stimulated by glucagon and adrenaline to in vivo episodes of hypoglycaemia. Methods. The blood glucose profile during an episode of insulininduced hypoglycaemia in exercised and nonexercised male Wistar control (GC) and food-restricted (GR, 50\%) rats and liver glucose release stimulated by glucagon and adrenaline were investigated. Results. In the GR, the hypoglycaemic episodes showed severe decreases in blood glucose, persistent hypoglycaemia, and less complete glycaemic recovery. An exercise session prior to the episode of hypoglycaemia raised the basal blood glucose, reduced the magnitude of the hypoglycaemia, and improved the recovery of blood glucose. In fed animals of both groups, liver glucose release was activated by glucagon and adrenaline. In fasted GR rats, liver glycogenolysis activated by glucagon was impaired, despite a significant basal glycogenolysis, while an adrenaline-stimulated liver glucose release was recorded. Conclusions. The lack of liver response to glucagon in the GR rats could be partially responsible for the more severe episodes of hypoglycaemia observed in vivo in nonexercised animals. The preserved liver response to adrenaline can partially account for the less severe hypoglycaemia in the food-restricted animals after acute exercise.

\section{Introduction}

The liver is a central organ for the regulation of energy homeostasis in general and blood glucose homeostasis in particular. It responds directly and autonomously to blood glucose concentration $[1,2]$ and is as well a central target of the neural and hormonal factors controlling energy metabolism; while insulin promotes glycogen synthesis and glycolysis in the liver, the counterregulatory hormonesglucagon, adrenaline, cortisol, and growth hormone-are glycogenolytic and gluconeogenic $[3,4]$. Together with their extrahepatic actions, the counterregulatory hormones tend to increase the blood glucose level, while the actions of insulin on the liver and other tissues are hypoglycaemic.
When glucose drops below the physiologically acceptable range, the counterregulatory system increases the production/release of glucose to be used, primarily by the brain, and supplies alternative energy substrates for the other tissues [3]. In this scenario, glucagon, because of its fast-acting effects on the liver, represents the first line of defence against hypoglycaemia [4].

During exercise, liver release of glucose helps to keep blood glucose within normal limits. This comes from glycogenolysis when glycogen stores are available $[5,6]$, especially during short-term moderate- to high-intensity exercises [2]. Although exercise activates many counterregulatory agents $[7,8]$, the increased blood levels of catecholamines deserve mention $[7,9,10]$. 
In adult rats raised under food restriction, hypoglycaemic episodes are characterized by severe decrease in blood glucose levels, persistent hypoglycaemia, and less complete glycaemic recovery [11], probably as a result of increased insulin sensitivity and impaired activation of the counterregulatory hormones [12-14]. However, it was observed that acute exercise has a positive effect on this hypoglycaemic profile: an exercise session previous to an episode of hypoglycaemia in these animals raised the basal blood glucose level, reduced the rate of decrease and the magnitude of the hypoglycaemia, and improved the recovery of the normal blood glucose level [15].

As the liver is an important metabolic centre for the regulation of blood glucose, we hypothesized that the counterregulation of hypoglycaemia and its hepatic effects, which seem to be compromised in animals under food restriction, could be potentiated by exercise, giving rise to less severe hypoglycaemic profiles in exercised compared to nonexercised animals [15]. Therefore, we reevaluated the blood glucose profile during an episode of insulin-induced hypoglycaemia (IIH) in exercised and nonexercised rats and investigated the liver glucose release stimulated by glucagon and adrenaline, hormones with hyperglycaemic actions on the liver that are relevant during hypoglycaemia and exercise. Our purpose was to correlate the liver glucose release stimulated by glucagon and adrenaline with the profiles of IIH recorded in vivo.

\section{Materials and Methods}

2.1. Experimental Groups. The Wistar dams and their puppies were kept in the animal house of the Department of Physiological Sciences under controlled light: dark cycles $(12 \mathrm{~h}$ $\mathrm{L}: 12 \mathrm{~h} \mathrm{D})$ and temperature $\left(22 \pm 2^{\circ} \mathrm{C}\right)$. All the procedures were approved by the Commission on Ethics in Animal Experimentation of the University and are in accordance with EU Directive 2010/63/EU for animal experiments.

Newborn litters were organized so that each dam had either six or 12 puppies (control group: GC; restriction group: $\mathrm{GR}$, resp.). The mothers had free access to water and chow (Nuvilab CR1; Nuvital, Curitiba, PR, Brazil) during gestation and lactation.

After weaning, at the age of 21 days, the puppies were kept in plastic boxes in groups of four animals. The GC rats had a free supply of water and chow, while those in the GR were subjected to a food restriction of $50 \%[11,16,17]$ until the age of 50-60 days, when the experiments were carried out. Only males were used in this investigation.

\subsection{Insulin-Induced Hypoglycaemia (IIH): In Vivo Experi-} ments. For the IIH experiments, preceded or not by exercise, the animals were fasted overnight (approx. 14 hours). The next morning they were injected i.p. with regular insulin (1 U. $\mathrm{kg}^{-1}$ b.w.; Novolin; Novo Nordisk, Montes Claros, MG, Brazil) [11]. Blood samples were collected from the tail vein at $0,15,30,60,120,180,240$, and $300 \mathrm{~min}$, time 0 being the moment immediately before the insulin injection. Blood glucose was determined with a glucometer (Optium Xceed, Abbott, Witney, UK).

2.3. Session of Acute Exercise: In Vivo Experiments. Some of the rats from both groups were subjected to exercise before IIH (groups GCex and GRex). The exercise session consisted of a run in an adapted programmed treadmill (KT3000, Inbramed, Porto Alegre, RS, Brazil). The treadmill speed increased $0.2 \mathrm{~km} \cdot \mathrm{h}^{-1}$ every two minutes from an initial speed of $0.4 \mathrm{~km} \cdot \mathrm{h}^{-1}$ and continued until exhaustion. This was established as the moment when the animals could not keep up with the treadmill speed or stopped running completely, characterizing an acute session of exercise.

2.4. Liver Glucose Release: In Situ Liver Perfusion. For the experiments of in situ liver perfusion, the rats, either fed or under overnight fasting, were anesthetized by i.p. injection of sodium thiopental ( $40 \mathrm{mg} \cdot \mathrm{kg}^{-1}$ b.w.) and had both the portal vein and inferior cava vein cannulated. The liver was perfused with Krebs-Henseleit buffer $\left(\mathrm{KH}, \mathrm{pH} 7.4,37^{\circ} \mathrm{C}\right)$ in a nonrecirculating system. The perfusion fluid was pumped through a membrane oxygenator saturated with $\mathrm{O}_{2} / \mathrm{CO}_{2}(95 / 5 \%)$ before entering the liver through the portal vein. Immediately after the beginning of the perfusion, the diaphragm was opened and the thoracic portion of the inferior cava vein was ligated [11, 17].

After 30 min of stabilization, during which the liver was perfused with $\mathrm{KH}$, samples of the effluent fluid were collected through the inferior cava vein each $5 \mathrm{~min}$. During the period of collection the liver was perfused for $10 \mathrm{~min}$ with $\mathrm{KH}$ (basal perfusion) and then with $\mathrm{KH}$ containing glucagon (1 nM for 20 min; Glucagen, Novo Nordisk, Montes Claros, MG, Brazil) or adrenaline $(1 \mu \mathrm{M}$ for $30 \mathrm{~min}$; Adren, Hipolabor, Belo Horizonte, MG, Brazil) (stimulated perfusion) [18, 19]. Some of the perfusion experiments with adrenaline were carried out in overnight fasted GC or GR animals immediately after an acute session of exercise.

The concentrations of glucose [20], lactate [21], and pyruvate [22] in the samples were determined spectrophotometrically and calculated as $\mu \mathrm{mol} \cdot \mathrm{min}^{-1} \cdot \mathrm{g}^{-1}$ liver. Based on the values obtained during basal and stimulated perfusion, the area under the curve (AUC) of the liver release of each compound was calculated and expressed as $\mu \mathrm{mol} \cdot \mathrm{g}^{-1}$ liver. Figure 1 illustrates liver glucose release during basal and stimulated perfusion with adrenaline in a fed control rat. The AUCs in this investigation were calculated from similar experiments.

The means of the AUCs of lactate and pyruvate in the adrenaline-stimulated perfusion were used to calculate the rates of glycolysis (= pyruvate + lactate) and glycogenolysis $[=$ glucose $+1 / 2$ (pyruvate + lactate) $]$ of the groups [23] .

2.5. Statistical Analysis. The data were treated statistically using the nonpaired Student's $t$-test. Values of $P<0.05$ were considered significant. The statistical analyses were carried out using Prism 5.01 (GraphPad software, San Diego, CA, USA). The data are shown as mean \pm standard deviation (SD). 
TABLE 1: AUCs for the liver release of glucose in the fed state.

\begin{tabular}{lcccc}
\hline & \multicolumn{2}{c}{ Glucagon 1 nM } & \multicolumn{2}{c}{ Adrenaline 1 $\mu \mathrm{M}$} \\
& GC & GR & GC & GR \\
\hline Basal perfusion $\left(\mu \mathrm{mol} \cdot \mathrm{g}^{-1}\right)$ & $6.01 \pm 1.85$ & $10.38 \pm 2.56$ & $26.24 \pm 9.28$ & $24.39 \pm 6.18$ \\
Stimulated perfusion $\left(\mu \mathrm{mol} \cdot \mathrm{g}^{-1}\right)$ & $10.14 \pm 3.46^{*}$ & $24.10 \pm 2.24^{\# \S}$ & $64.78 \pm 0.93^{@}$ & $59.6 \pm 12.05^{@}$ \\
\hline
\end{tabular}

Data shown as mean \pm SD of $4-10$ observations.

${ }^{*} P<0.05$ compared with the basal perfusion in the GC; ${ }^{\#} P<0.01$ compared with the basal perfusion in the GR; ${ }^{\S} P<0.01$ compared with the stimulated perfusion in the GC; ${ }^{\circledR} P<0.01$ compared with the basal perfusion in the respective group.

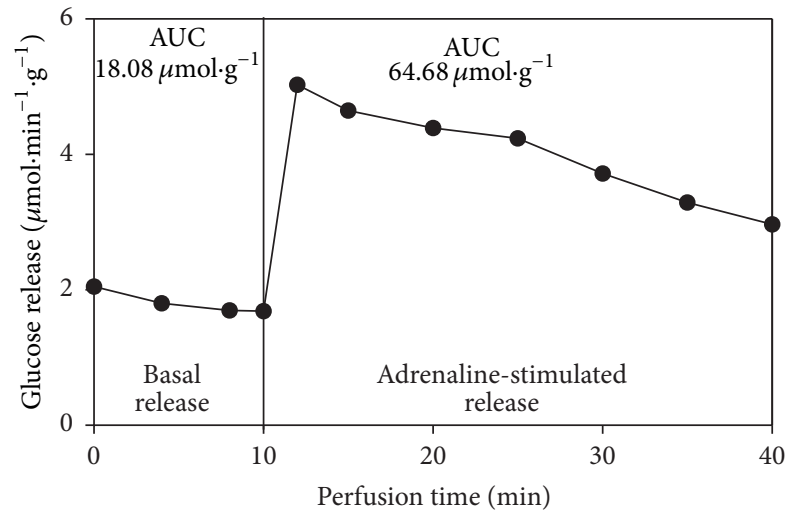

FIGURE 1: Illustrative graph of liver glucose release in a fed control rat, before (basal release) and during (stimulated release) perfusion with adrenaline $(1 \mu \mathrm{M})$. The vertical line indicates the transition from basal perfusion (KH only) to stimulated perfusion (KH with adrenaline $1 \mu \mathrm{M})$. The AUC of basal glucose release considered all glucose released during the 10 -min interval. AUC of stimulated release considered those glucose values above the basal release during the 30 -min interval.

\section{Results}

3.1. Insulin-Induced Hypoglycaemia. Figure 2 shows blood glucose profiles after overnight fasting of GC and GR rats during an episode of IIH preceded by rest Figure 2(a) or acute exercise Figure 2(b). The statistical analysis showed that the basal blood glucose (time $0 \mathrm{~min}$ ) in the GC and GR did not differ in the nonexercised animals $(P>0.05$, Figure 2(a)) but was significantly higher in the GRex than in the GCex $(P<0.01$, Figure $2(b))$. This is because basal blood glucose was reduced in the exercised control animals $\left(79.31 \pm 9.98 \mathrm{mg} \cdot \mathrm{dL}^{-1}\right.$ in the $\mathrm{GC}$ versus $67.08 \pm 5.12 \mathrm{mg} \cdot \mathrm{dL}^{-1}$ in the GCex, $P<0.05$ ), while it was increased in the exercised food-restricted group $\left(82.84 \pm 9.21 \mathrm{mg} \cdot \mathrm{dL}^{-1}\right.$ in the GR versus $92.21 \pm 8.09 \mathrm{mg} \cdot \mathrm{dL}^{-1}$ in the GRex, $\left.P<0.05\right)$ compared with their respective nonexercised groups.

In the nonexercised animals (GC and GR, Figure 2(a)), hypoglycaemia was already present $15 \mathrm{~min}$ after insulin injection and its lowest values were recorded at 60 and $120 \mathrm{~min}$. Blood glucose in the two groups did not differ during the first two hours $(P>0.05)$. However, blood glucose started to rise in the GC at $180 \mathrm{~min}$, while the GR showed only a slight recovery at $300 \mathrm{~min}$. Thus, blood glucose in the GR remained significantly lower than that in the GC $(P<0.01) 180 \mathrm{~min}$ after the injection of insulin.
After the exercise session (GCex and GRex, Figure 2(b)), insulin injection also caused a significant drop in blood glucose that continued from 15 to $60 \mathrm{~min}$, in both groups. The relative decrease in blood glucose was of the same magnitude in both exercised groups; however, the GRex showed higher absolute blood glucose values during the first $60 \mathrm{~min}$ of the IIH, so that the hypoglycaemic profile was markedly attenuated in the GRex compared with the GCex. The glycaemic recovery was significantly better in the GRex than in the GCex at 240 and $300 \mathrm{~min}(P<0.01)$.

3.2. Liver Glucose Release: Fed Animals. In the fed state, the basal release of glucose (i.e., before perfusion with glucagon or adrenaline) was high both in the GC and the GR. The perfusion with glucagon or adrenaline caused an additional, immediate, and sustained increase in liver glucose release.

The AUCs for the basal and stimulated perfusion with glucagon or adrenaline in the fed GC and GR animals are shown in Table 1. Glucagon increased liver glucose release in both groups, but in a more significant and sustained way in the GR compared with the GC $(P<0.01$ in the GR versus $P<$ 0.05 in the GC in comparison with the respective basal perfusion). The liver glucose release stimulated by adrenaline was markedly higher than the basal release in the fed GC and GR animals $(P<0.01)$ but was not different between the groups $(P>0.05)$.

3.3. Liver Glucose Release: Overnight Fasted Animals. After fasting and without a previous exercise session, the animals of the GR showed a high basal glucose release (Table 2), as observed in the fed state (Table 1); on the other hand, the basal glucose release of the GC was very low, so that basal glucose release after overnight fasting differed significantly between GC and GR $(P<0.01)$. In the overnight fasted GR, adrenaline significantly increased liver glucose release, but not in the fasted GC (Table 2). None of the fasted groups responded to the perfusion with glucagon.

Liver glucose release after the exercise session was increased by adrenaline in both groups $(P<0.01$, Table 3$)$. However, the values obtained for the exercised GR animals (Table 3) were much lower than those observed in the nonexercised GR (Table 2), both for the basal and stimulated perfusion. On the other hand, the basal and stimulated values did not differ statistically between the exercised (Table 3 ) and nonexercised animals (Table 2) in the GC.

Table 4 shows the liver release of pyruvate and lactate during the perfusion with adrenaline in the fasted GC and GR animals either subjected or not to an acute exercise session. 


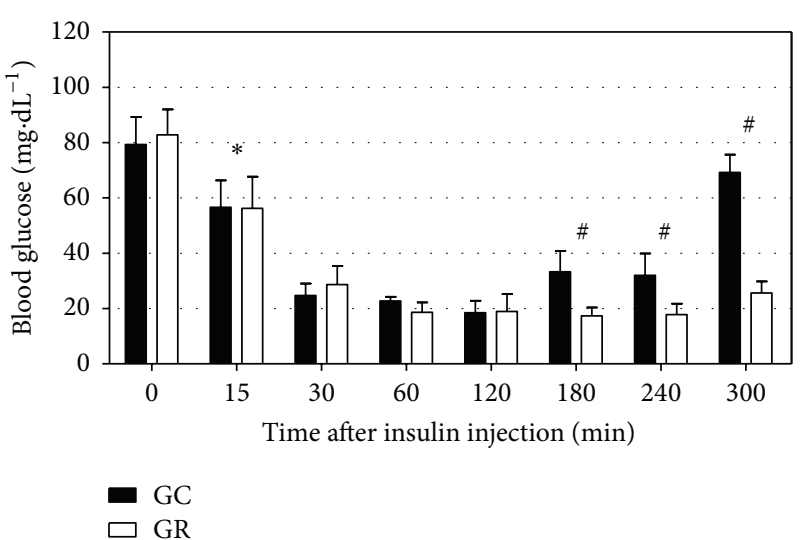

(a)

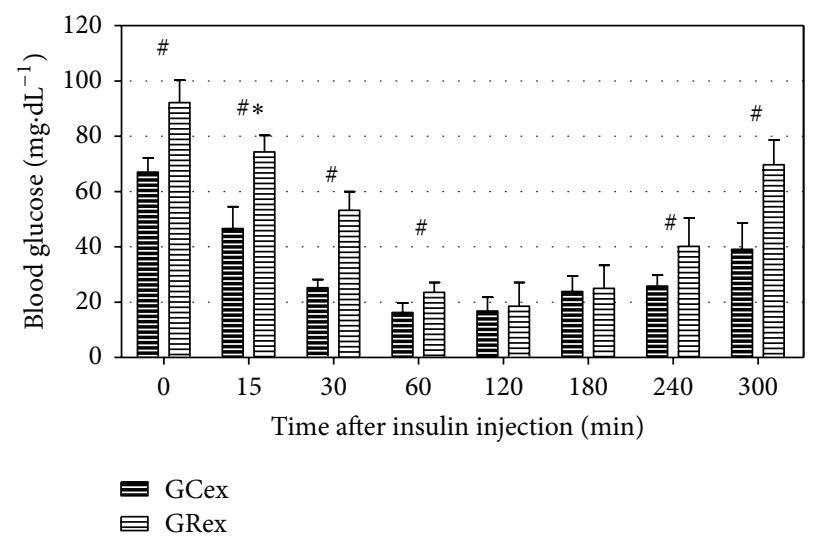

(b)

Figure 2: Blood glucose profiles of control and food-restricted rats during insulin-induced hypoglycaemia, either without exercise ((a), groups GC and GR) or after an acute exercise session ((b), groups GCex and GRex). Insulin was i.p. injected at time 0 min and blood glucose was recorded for $300 \mathrm{~min}$. Mean $\pm \mathrm{SD}$ of $6-12$ observations at each time. ${ }^{*} P<0.01$ compared with time 0 min of the same group; ${ }^{\#} P<0.01$ between groups at the same time, according to Student's $t$-test.

TABLE 2: AUCs for the liver release of glucose in the fasted state.

\begin{tabular}{lccrr}
\hline & \multicolumn{2}{c}{ Glucagon $1 \mathrm{nM}$} & \multicolumn{2}{c}{ Adrenaline $1 \mu \mathrm{M}$} \\
& GC & GR & GC & GR \\
\hline Basal perfusion $\left(\mu \mathrm{mol} \cdot \mathrm{g}^{-1}\right)$ & $1.86 \pm 0.71$ & $13.50 \pm 3.57^{*}$ & $0.82 \pm 0.40$ & $24.23 \pm 4.92^{*}$ \\
Stimulated perfusion $\left(\mu \mathrm{mol} \cdot \mathrm{g}^{-1}\right)$ & $0.27 \pm 0.02^{*}$ & $0^{@}$ & $0.92 \pm 0.71$ & $62.99 \pm 13.09^{\# @}$ \\
\hline
\end{tabular}

Data shown as mean \pm SD of $4-6$ observations.

${ }^{*} P<0.01$ compared with the basal perfusion in the GC; ${ }^{\#} P<0.01$ compared with the stimulated perfusion in the GC; ${ }^{\circledR} P<0.05$ compared with the basal perfusion in the GR.

TABLE 3: AUCs for the liver release of glucose in the fasted state after an acute exercise session.

\begin{tabular}{lcc}
\hline & GC & GR \\
\hline $\begin{array}{l}\text { Basal perfusion } \\
\left(\mu \mathrm{mol} \cdot \mathrm{g}^{-1}\right)\end{array}$ & $0.67 \pm 0.21$ & $1.35 \pm 0.25^{\#}$ \\
$\begin{array}{l}\text { Adrenaline-stimulated } \\
\text { perfusion }\left(\mu \mathrm{mol} \cdot \mathrm{g}^{-1}\right)\end{array}$ & $1.46 \pm 0.21^{*}$ & $2.67 \pm 0.37^{* \#}$ \\
\hline
\end{tabular}

Data shown as mean \pm SD of 4-7 observations.

${ }^{*} P<0.01$ compared with the basal perfusion in the same group; ${ }^{\#} P<0.05$ compared with the corresponding period in the GC.

Under adrenaline stimulation, the liver release of pyruvate was lower and that of lactate was higher in the GR than in the GC $(P<0.05)$. There were no differences in the liver release of either pyruvate or lactate between the exercised groups $(P>0.05$, Table 4$)$.

The calculated rates of glycolysis and glycogenolysis in the presence of adrenaline are shown in Table 5. The rate of glycolysis in the nonexercised animals was higher in the GR than in the GC, but it was similar between the groups that were exercised before the liver perfusion. The GR showed higher rates of glycogenolysis than the GC in both procedures (i.e., with or without exercise before the liver perfusion with adrenaline). However, there was a marked reduction in the rate of glycogenolysis in the exercised GR compared with the nonexercised GR.
In summary, the in vivo IIH experiments showed a worsened glycaemic recovery in the nonexercised GR rats (Figure 2(a)); on the other hand, the profile of the hypoglycaemia was attenuated and the blood glucose recovery was improved in the GR after an acute session of exercise (Figure 2(b)). Glucagon increased the liver glucose release only in fed animals (Table 1) but had no effect in fasted rats (Table 2). The liver response to the perfusion with adrenaline in the fasted GR (Table 2) was similar to that of the fed GR (Table 1), while the liver response to adrenaline in the fasted GC (Table 2) was insignificant. After the acute exercise session, a response to adrenaline was recorded in both groups, although it was more marked in the GR (Table 3). The liver glucose release in the exercised GR, both during the basal and the stimulated perfusion (Table 3), was significantly less than that recorded in the nonexercised GR animals (Table 2). In the absence of exercise, the fasted GR showed higher rates of glycogenolysis and glycolysis (Table 5) and higher liver release of lactate (Table 4). The acute session of exercise made these parameters equal between the GC and the GR during both the basal and the adrenaline-stimulated liver perfusion.

\section{Discussion}

This work aimed at investigating whether liver glucose release and its stimulation by adrenaline and glucagon (Table 2) 
TABLE 4: AUCs for the liver release of pyruvate and lactate.

\begin{tabular}{|c|c|c|c|c|}
\hline \multirow{2}{*}{ Perfusion procedure } & \multicolumn{2}{|c|}{ Pyruvate $\left(\mu \mathrm{mol} \cdot \mathrm{g}^{-1}\right)$} & \multicolumn{2}{|c|}{ Lactate $\left(\mu \mathrm{mol} \cdot \mathrm{g}^{-1}\right)$} \\
\hline & GC & GR & GC & GR \\
\hline Adrenaline $1 \mu \mathrm{M}$ & $0.039 \pm 0.02$ & $0^{*}$ & $0.654 \pm 0.30$ & $1.269 \pm 0.44^{*}$ \\
\hline Exercise + Adrenaline $1 \mu \mathrm{M}$ & $0.131 \pm 0.07$ & $0.138 \pm 0.03$ & $2.366 \pm 0.46$ & $2.027 \pm 0.87$ \\
\hline
\end{tabular}

Data shown as mean \pm SD of 4-8 observations.

${ }^{*} P<0.05$ compared with the GC with the same procedure.

TABLE 5: Rates of glycolysis and glycogenolysis* .

\begin{tabular}{llcr}
\hline & & & Perfusion procedure \\
& & Exercise + Adrenaline $1 \mu \mathrm{M}$ \\
\hline & GCb & Adrenaline $1 \mu \mathrm{M}$ & 1.57 \\
Rate of glycolysis $\left(\mu \mathrm{mol} \cdot \mathrm{g}^{-1}\right)$ & GRb & 10.72 & 1.99 \\
& GCst & 0.70 & 2.50 \\
& GRst & 1.27 & 2.17 \\
Rate of glycogenolysis $\left(\mu \mathrm{mol} \cdot \mathrm{g}^{-1}\right)$ & GCb & 1.18 & 1.46 \\
& GRb & 29.69 & 2.34 \\
& GCst & 1.58 & 2.71 \\
\hline
\end{tabular}

${ }^{*}$ Calculated as described in Section 2.4 .

could explain the change in the profile of the insulininduced hypoglycaemia observed in vivo in food-restricted rats subjected to an acute exercise session (Figure 2(b)).

The in vivo experiments in this investigation reinforce the observations previously made [15]: first, that nonexercised food-restricted animals have episodes of hypoglycaemia that are severe and show incomplete recovery and, second, that the exercise session until exhaustion increases the basal blood glucose, decreases the severity of the hypoglycaemia, and improves the glycaemic recovery $[5-7,9,11,15]$. A heightened sensitivity to insulin and an impaired counterregulation $[11,13,14]$ were suggested as possible agents behind the observations in the nonexercised animals; improvement in the actions of some counterregulatory hormones by exercise was suggested as an explanation for the latter instance.

The fall in blood glucose after the exercise session in the GCex and its rise in the GRex (Figure 2(b)) can be partially accounted for by the liver content of glycogen: the presence of glycogen in the liver is related to postexercise hyperglycaemia, while its absence leads to hypoglycaemia [24]. In this study, the fasted GC animals showed low glycogenolysis (assessed by the basal liver glucose release, Table 2), while those of the GR had a basal liver glucose release in the fasted state (Table 2) as high as in the fed state (Table 1).

The fact that all the fed animals responded to glucagon and adrenaline with a marked increase in liver glucose release indicates that the responsiveness of the hepatocytes to these hormones was not impaired. In addition, the high basal liver glucose release in the fed groups indicates the presence of glycogen. Both observations are expected during the postprandial period $[19,24,25]$.

The high basal liver glucose release in the fasted GR has already been observed $[11,13,17]$ and suggests that the nutritional condition of these animals (reduced supply of food since birth) changes the turnover of liver glycogen so that glycogenolysis can be detected even after many hours of fasting [19]. The rates of glycolysis and glycogenolysis in the GR during the basal perfusion (Table 5) are in agreement with those arguments. As the animals were given food at random time intervals, the more persistent storage of glycogen cannot be attributed to metabolic programming [26].

During a hypoglycaemic episode, glucagon is one of the first hyperglycaemic agents [4]. In the fasted nonexercised GR animals, the absent response of the liver to the perfusion with glucagon (Table 2), despite the marked basal glycogenolysis, could partially explain the impaired glycaemic recovery observed in the in vivo experiments (Figure 2(a)). The fasted GC animals did not respond to the perfusion with glucagon either (Table 2); however, it is possible that, in these freely fed animals, having significant fat stores and well-developed skeletal muscle mass [16], extrahepatic counterregulatory actions, such as greater lipid mobilization and oxidation of fatty acids, may contribute to their improved glycaemic recovery. On the other hand, the GR, with reduced adipose tissue $[8,16]$, would be more dependent on liver glucose release to counteract a hypoglycaemic challenge.

The liver of the fasted GR increased glucose release in response to adrenaline in a fashion very similar to that observed in the fed animals (Tables 2 and 1, resp.). As liver glycogen is an important cause of postexercise hyperglycaemia [24], it can be hypothesized that, in vivo, the adrenaline released by exercise would be capable of accentuating liver glycogenolysis, resulting in higher postexercise glycaemia and better glycaemic recovery during the hypoglycaemic episode in the animals under food restriction. Consistent with this, both the basal and adrenalinestimulated liver glucose release by the exercised GR were 
markedly lower than those of the nonexercised GR rats. In addition, the nonexercised GR showed both a high rate of glycolysis and a high liver release of lactate. Taken together, these results suggest a considerable decrease in liver glycogen caused by the previous strenuous exercise. More than that, the rates of glycogenolysis in the GR were higher than those in the GC regardless of the exercise but were much less in the previously exercised GR compared with the nonexercised GR animals.

\section{Conclusion}

In rats under food restriction since birth, liver glycogenolysis stimulated by glucagon was impaired. This could be partially responsible for the impaired glycaemic recovery observed during in vivo hypoglycaemia. On the other hand, the adrenaline-stimulated liver glycogenolysis was preserved and can partially account for the improved glycaemic profile observed during hypoglycaemia in the food-restricted animals after an acute session of exercise. The results are relevant to individuals under food restriction in the sense that exercise could be beneficial to counteract occasional episodes of hypoglycaemia.

\section{Conflict of Interests}

The authors declare that there is no conflict of interests regarding the publication of this paper.

\section{Acknowledgments}

This study had financial support from the Fundação de Apoio ao Desenvolvimento Científico (FADEC). The authors thank Elizete dos Santos, Márcia Fabrício, and Valéria Romão for their technical assistance.

\section{References}

[1] M. C. Moore, C. C. Connolly, and A. D. Cherrington, "Autoregulation of hepatic glucose production," European Journal of Endocrinology, vol. 138, no. 3, pp. 240-248, 1998.

[2] J. Wahren and K. Ekberg, "Splanchnic regulation of glucose production," Annual Review of Nutrition, vol. 27, pp. 329-345, 2007.

[3] R. P. Hoffman, "Sympathetic mechanisms of hypoglycemic counterregulation," Current Diabetes Reviews, vol. 3, no. 3, pp. 185-193, 2007.

[4] I. Lager, "The insulin-antagonist effect of the counterregulatory hormones," Journal of Internal Medicine, Supplement, vol. 229, no. 735, pp. 41-47, 1991.

[5] B. Sonne and H. Galbo, "Carbohydrate metabolism during and after exercise in rats: studies with radioglucose," Journal of Applied Physiology, vol. 59, no. 5, pp. 1627-1639, 1985.

[6] S.-H. Suh, I.-Y. Paik, and K. A. Jacobs, "Regulation of blood glucose homeostasis during prolonged exercise," Molecules and Cells, vol. 23, no. 3, pp. 272-279, 2007.

[7] M. Afonso, C. N. de Souza, A. M. Zagatto, and E. Luciano, "Respostas metabólicas agudas ao exercício físico moderado em ratos wistar," Motriz, vol. 9, pp. 87-92, 2003.
[8] M. V. Giampietro, Alterações metabólicas em ratos desnutridos em resposta ao treinamento de endurance, University of São Paulo, São Paulo, Brazil, 2007.

[9] M. Kjaer, B. Kiens, M. Hargreaves, and E. A. Richter, "Influence of active muscle mass on glucose homeostasis during exercise in humans," Journal of Applied Physiology, vol. 71, no. 2, pp. 552$557,1991$.

[10] A. E. Lima-Silva, T. C. Fernandes, F. R. de Oliveira, F. Y. Nakamura, and M. S. Gevaerd, "Metabolismo do glicogênio muscular durante o exercício físico: mecanismos de regulação," Revista de Nutrição de Campinas, vol. 20, pp. 417-429, 2007.

[11] A. Malta, M. P. Furlan, A. S. Vitoriano, H. C. Barrena, R. B. Bazotte, and V. G. Gazola, "Insulin sensitivity and liver glucose production in the rat are influenced by lifetime food restriction," Nutrition Research, vol. 30, no. 9, pp. 626-631, 2010.

[12] N. Barzilai, L. She, B.-Q. Liu et al., "Surgical removal of visceral fat reverses hepatic insulin resistance," Diabetes, vol. 48, no. 1 , pp. 94-98, 1999.

[13] T. Leon-Quinto, P. Adnot, and B. Portha, "Alteration of the counterregulatory hormones in the conscious rat after proteinenergy restriction," Diabetologia, vol. 40, no. 9, pp. 1028-1034, 1997.

[14] T. Leon-Quinto, C. Magnan, and B. Portha, "Altered activity of the autonomous nervous system as a determinant of the impaired $\beta$-cell secretory response after protein-energy restriction in the rat," Endocrinology, vol. 139, no. 8, pp. 3382-3389, 1998.

[15] A. Malta, Metabolismo sistêmico da glicose em ratos jovens desnutridos desde o nascimento submetidos a exercício físico, State University of Maringá, Maringá, Brazil, 2010.

[16] M. R. Vismara and M. M. D. P. Furlan, "Parâmetros biométricos como indicadores do grau de desnutrição em ratos sob restrição alimentar desde o nascimento," Arquivos de Ciências da Saúde da Unipar, vol. 11, pp. 3-8, 2007.

[17] A. D. S. Vitoriano, A. Malta, H. C. Barrena, M. M. D. P. Furlan, R. B. Bazotte, and V. G. Gazola, "Blood glucose regulation during fasting in rats under food restriction since birth," Brazilian Archives of Biology and Technology, vol. 54, no. 1, pp. 67-72, 2011.

[18] R. B. Bazotte, J. Constantin, N. S. Hell, E. L. I. Iwamoto, and A. Bracht, "The relation between inhibition of glycolysis and stimulation of oxygen uptake due to glucagon in livers from rats in different metabolic conditions," Cell Biochemistry and Function, vol. 6, no. 4, pp. 225-230, 1988.

[19] R. B. Bazotte, J. Constantin, R. Curi, F. S. Kemmelmeier, N. S. Hell, and A. Bracht, "The sensitivity of glycogenolysis to glucagon, epinephrine and cyanide in livers from rats in different metabolic conditions," Research Communications in Chemical Pathology and Pharmacology, vol. 64, no. 2, pp. 193203, 1989.

[20] H. U. Bergmeyer and E. Bernt, "Determination of glucose with glucose-352 oxidase and peroxidase," in Methods of Enzymatic Analysis, Verlag Chemie-Academic Press, New York, NY, USA, 1974.

[21] I. Gutmann and W. Wahlefeld, "L-(+)-Lactate. Determination with lactate dehydrogenase and NAD," in Methods of Enzymatic Analysis, Verlag Chemie-Academic Press, New York, NY, USA, 1974.

[22] R. Czok and W. Lamprecht, "Pyruvate, phosphoenolpyruvate and D-glycerate-2-phosphate," in Methods of Enzymatic Analysis, Verlag Chemie-Academic Press, New York, NY, USA, 1974.

[23] M. Vardanega-Peicher, R. Curi, S. Pagliarini e Silva, K. F. Nascimento, and R. B. Bazotte, "Responsiveness of glycogen 
breakdown to cylic AMP in perfused liver from rats with insulin-induced hypoglycemia," Brazilian Journal of Medical and Biological Research, vol. 36, no. 1, pp. 45-51, 2003.

[24] G. R. Borba-Murad, "Changes in glycemia induced by exercise in rats: contribution of hepatic glycogenolysis and gluconeogenesis," Research Communications in Molecular Pathology and Pharmacology, vol. 102, no. 2, pp. 113-123, 1998.

[25] U. Beuers and K. Jungermann, "Relative contribution of glycogenolysis and gluconeogenesis to basal, glucagon- and nerve stimulation-dependent glucose output in the perfused liver from fed and fasted rats," Biochemistry International, vol. 21, no. 3, pp. 405-415, 1990.

[26] R. B. Bazotte, R. Curi, and N. S. Hell, "Metabolic changes caused by irregular-feeding schedule as compared with meal-feeding," Physiology and Behavior, vol. 46, no. 2, pp. 109-113, 1989. 


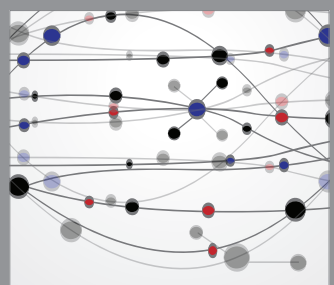

The Scientific World Journal
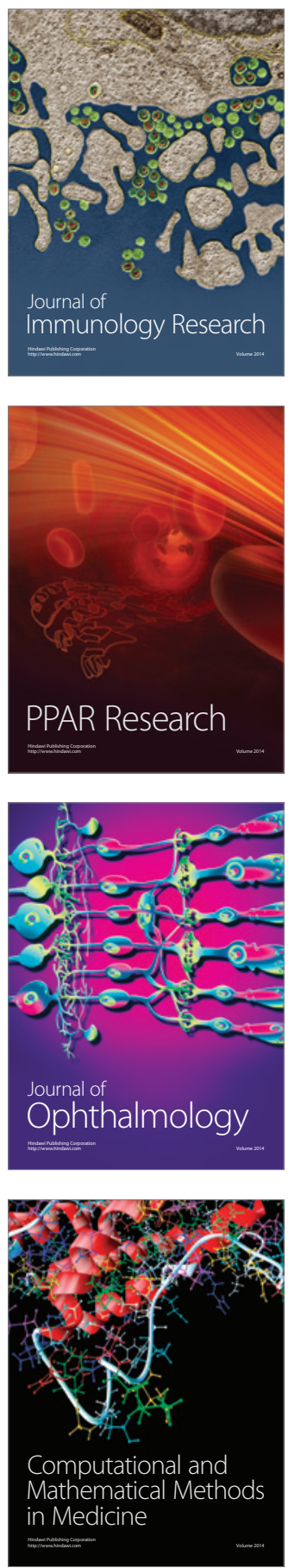

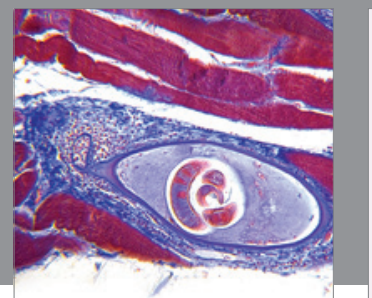

Gastroenterology

Research and Practice
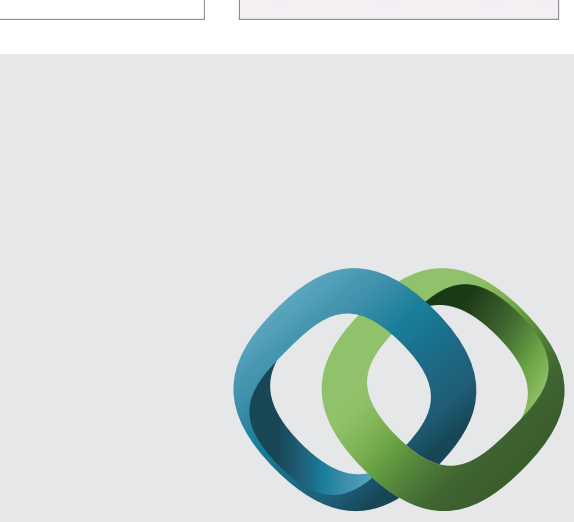

\section{Hindawi}

Submit your manuscripts at

http://www.hindawi.com
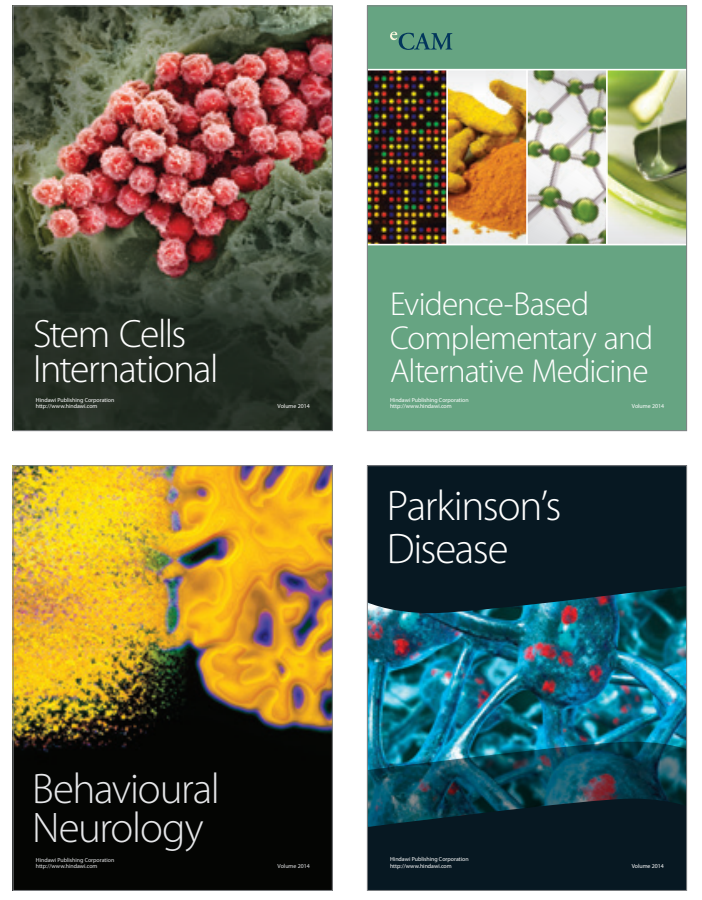
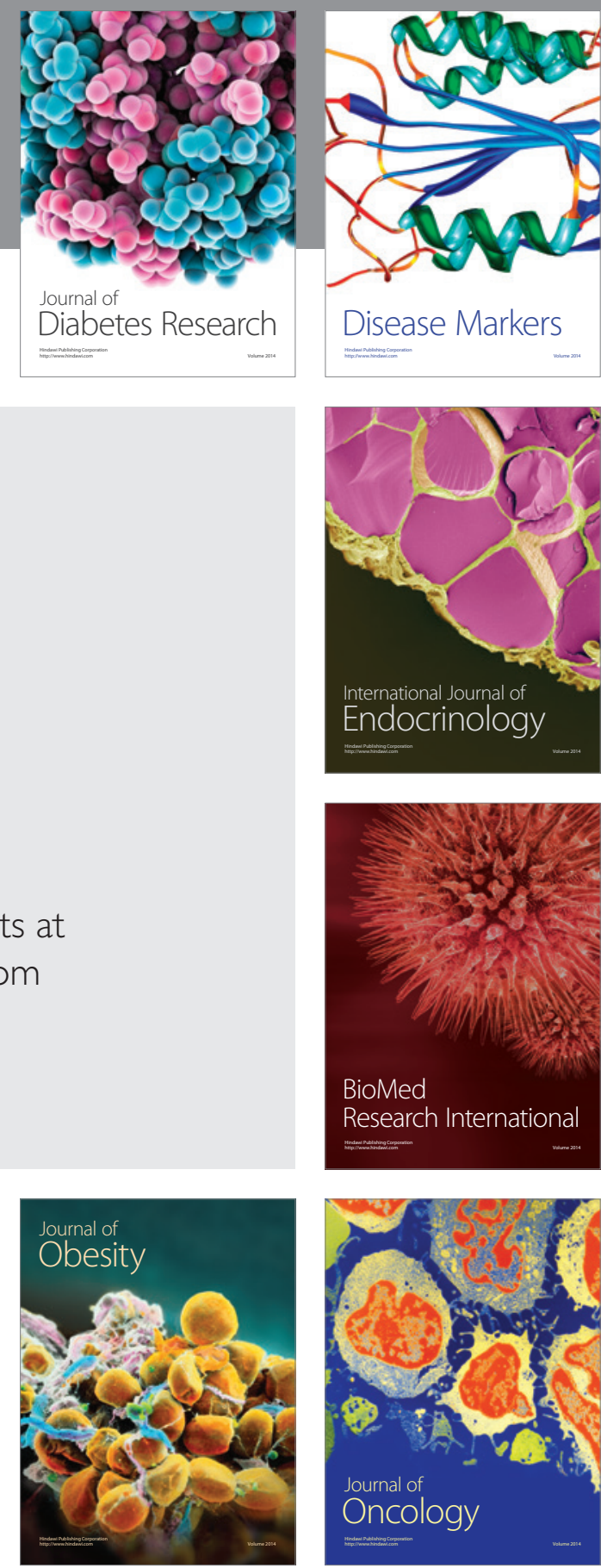

Disease Markers
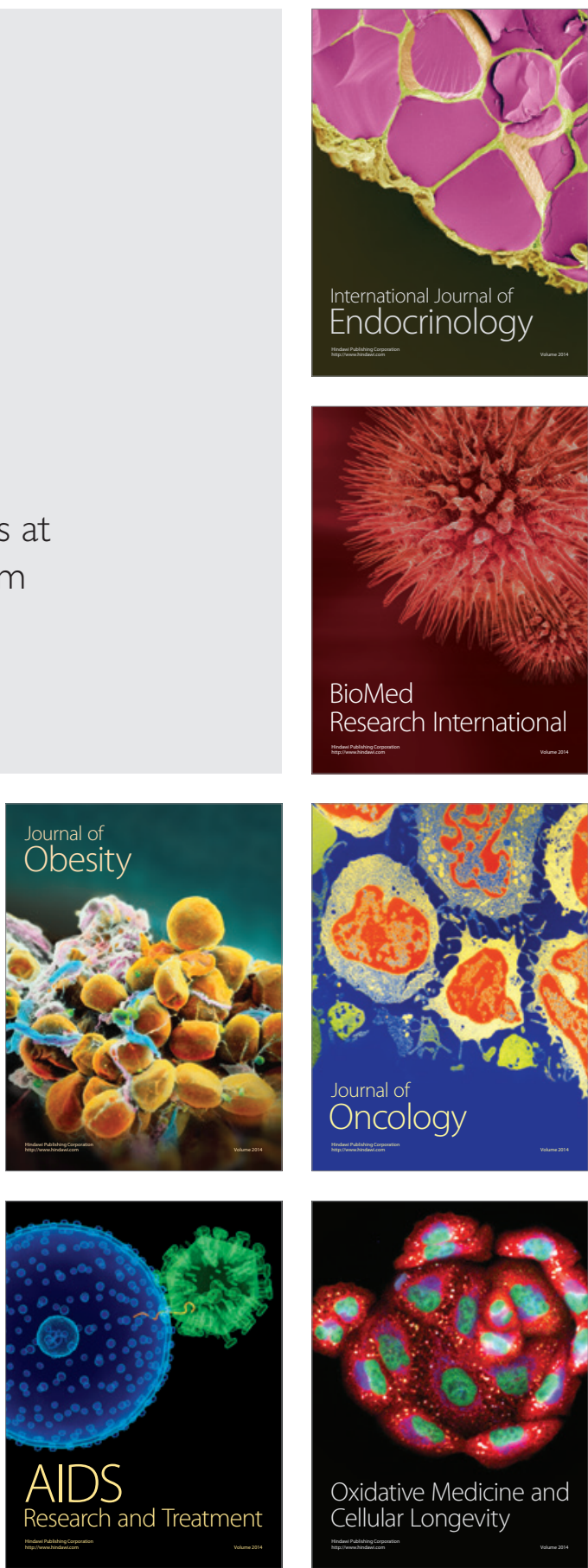